\title{
電子物性におけるリーマン幾何学効果
}

\author{
尾上順 \\ 東京工業大学原子炬工学研究所＼cjkstart恶 152-8550 東京都目黒区大岡山 2 丁目 12-1
}

（2012 年 9 月 25 日受付；2012 年 10 月 4 日掲載決定）

\section{Riemannian Geometrical Effects on the Electronic Properties of Condensed Matters}

\author{
Jun ONOE
}

Tokyo Institute of Technology, 2-12-1 O-okayama, Meguro-ku, Tokyo 152-8550

(Received September 25, 2012 ; Accepted October 4, 2012)

\begin{abstract}
A. Einstein first applied Riemannian geometry to develop the general theory of relativity almost one hundred years ago and succeeded in understanding astronomical-scale phenomena such as the straining of time-space by a gravitational field. It is of great interest to reveal whether or not Riemannian geometry affects the electronic properties of condensed matters on a much smaller scale. Although Riemannian geometry has been applied to quantum mechanics since the 1950s, nobody has yet answered this question, because the electronic properties of materials with Riemannian geometry have not been examined experimentally. We report here the prediction and observation of Riemannian geometrical effects on the electronic properties of one-dimensional metallic uneven peanut-shaped $\mathrm{C}_{60}$ polymer.
\end{abstract}

KEYWORDS : one-dimensional peanut-shaped $\mathrm{C}_{60}$ polymer, Riemannian geometric effects, Tomonaga-Luttinger liquid, photoemission spectroscopy, Gaussian curvature

\section{1.は じめに}

1916 年，アインシュタインはリーマン幾何学を取り 入れることにより一般相対論を完成させ，重力場により 時空間が歪むことを予想した ${ }^{1)} 。 1920$ 年, 光の重力レン

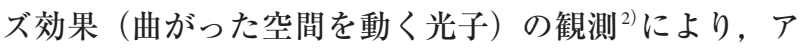
インシュタインの予想は見事に実証された。

1950 年代に, リーマン幾何学（簡単に言えば，曲が った空間を取り扱う幾何学のこと）を取り入れた量子力 学が取り扱われ ${ }^{3)}$, 周期的凹凸曲面上の粒子の運動エネ ルギー項の中に理論上現れる幾何曲率項が電子物性に影 響するかどうか興味が持たれてきたが，この幾何曲率効 果（リーマン幾何学効果）を発現しそうな周期的凹凸曲 面をもった物質が無かったため, 効果の有無を実証でき なかった。この状況は電磁気学で現れるべクトルポテン シャルと良く似ている。ベクトルポテンシャルは長年数 学的に導入されたものと考えられてきたが，アハラノフ とボームによりベクトルポテンシャルが電子の波動関数

E-mail : jonoe@nr.titech.ac.jp
の位相に影響することを理論的に示し $(\mathrm{AB} \text { 効果 })^{4)}$ ，そ の後電子線ホログラフィーを用いて，外村らにより $\mathrm{AB}$ 効果が実証された

筆者らは，超高真空下で作製した $\mathrm{C}_{60}$ 薄膜に電子線を 照射することにより，Fig. 1 に示すような 1 次元（1D） 周期的凹凸曲面構造を有するポリマーが生成することを 見いだしてきた ${ }^{6 \sim 18)}$ 。

このナノカーボンは幾何学的な観点から興味深い（ト ーラス構造等トポロジカルな構造をもつ物質について は，本誌手塚氏の解説記事を参照されたい)。Table 1 に 幾何学数量であるガウス曲率 $k^{19)}$ を用いて，ナノカーボ ンファミリーを整理した。グラフェンは $k=0$, ナノチ ユーブは $k=0$ （両端がキャップされている場合は, 端 の部分のみ $k>0)$, フラーレンは $k>0$ と分類される。 このほかに, 仮想構造として, $k<0$ をもつ Mackay 結 晶 ${ }^{20}$ が提案され（合成に成功した報告例はない）, 負の ガウス曲率曲面により磁性が発現することが理論予想さ れている ${ }^{21)}$ 。Fig. 1 に示す 1 次元周期的凹凸曲面構造を 有する $\mathrm{C}_{60}$ ポリマーは, 正と負のガウス曲率を有する実 在する物質であることから, フラーレン, ナノチュー 
尾上順

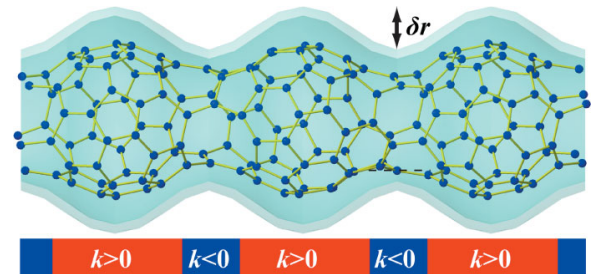

Fig. 1. (color online). Schematic illustration of a onedimensional metallic $\mathrm{C}_{60}$ polymer with an uneven peanutshaped structure [Ref. 18)]. Here, $\delta r$ denotes the degree of uneven deformation, and $k$ is a Gaussian curvature.

Table 1. (color online). Classification of nanocarbon allotropes based on Gaussian curvature[Ref. 18)]. Here, "+" and "-" indicate positive and negative, respectively.

\begin{tabular}{cc}
\hline $\begin{array}{c}\text { Nanocarbon } \\
\text { allotropes }\end{array}$ & $\begin{array}{c}\text { Gaussian } \\
\text { curvature } k\end{array}$ \\
\hline graphene & 0 \\
fullerenes & + \\
nanotubes & $\begin{array}{c}\text { (body), } \\
\text { (cap) }\end{array}$ \\
$\begin{array}{c}\text { Mackay } \\
\text { crystal } \\
\text { (hypothetical) }\end{array}$ & - \\
\hline $\begin{array}{l}\text { 1D } \\
\text { peanut-shaped } \\
\text { polymer }\end{array}$ &,+- \\
\hline
\end{tabular}

ブ，グラフェンにはない曲率を持ち，これらとは異なる 物性を示すことが期待される。

筆者らは，まず始めに 1D 中空チューブ表面を動く自 由電子系を用いて, 幾何曲率が具体的に物性值にどのよ うに影響するかを，電子物性の一つである TomonagaLuttinger 液体挙動を特徵づける指数 $\alpha$ について調べ, 周期的凹凸度 $(\delta r)$ に対する依存性を理論予測した ${ }^{13)}$ 。 次に, Fig. 1 に示す $1 \mathrm{D}$ 周期的凸凹曲面 $\mathrm{C}_{60}$ ポリマーの 光電子スペクトルの温度依存性の解析から求めた指数 $\alpha$ の值が理論予測と一致することを示し, 電子物性に対す るリーマン幾何学効果を初めて実証することに成功し た ${ }^{18)}$ 。本稿では, これらの研究成果を紹介し, 最後に現 代幾何学と物質科学との新たな融合分野への展望につい て触れる。本誌 2009 年 12 月号に「曲面量子系のサイエ ンス」が特集されており, 合わせて参照されたい22)。

\section{2. 電子に対するリーマン幾何学効果}

1D 凹凸周期曲面上を動く電子はユークリッド空間よ

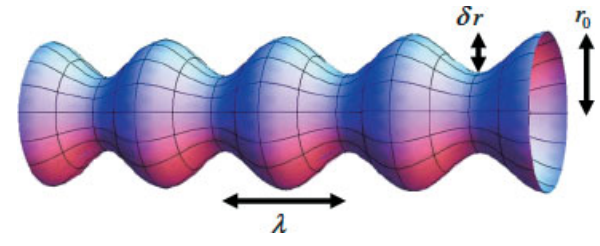

Fig. 2. (color online). Schematic 1D hollow tube with a periodic deformed modulation [Ref. 13)].

りもリーマン空間で取り扱うほうが物理的意味を理解し やすい。これは, 水素原子の電子の振る舞いを取り扱う 場合と似ている。水素原子をシュレディンガー方程式で 解く際に, 電子の空間座標をデカルト座標 $(x, y, z)$ から極座標 $(r, \theta, \phi)$ に変換する。この座標変換によ り, 電子の運動エネルギーに関係するラプラス演算子 $\triangle$ は,

$$
\triangle=\frac{\partial^{2}}{\partial x^{2}}+\frac{\partial^{2}}{\partial y^{2}}+\frac{\partial^{2}}{\partial z^{2}}
$$

から

$$
\triangle=\frac{1}{r^{2}} \frac{\partial}{\partial r}\left(r^{2} \frac{\partial}{\partial r}\right)+\frac{1}{r^{2}} \Lambda
$$

と変換される。ここで， $\Lambda$ はルジャンドル演算子を表 す。座標変換することにより，動径に関する演算子（第 1 項）と角度に関する演算子（第 2 項）に分けることが でき，その結果，電子の波動関数はエネルギーや存在確 率に関係する動径関数とオービタルの形に関係する球面 調和関数の積で表され, 波動関数の物理的意味が容易に 理解できる ${ }^{23)}$ 。

いま簡単のために, 1D 金属ピーナッツ型フラーレン ポリマーの電子の動きを炭素原子のネットワークを無視 して（次節 Fig. 7 で炭素原子ネットワークを考慮した場 合について述べる), Fig. 2 に示すような滑らかな 1D 凹 凸周期曲面上を動く電子に焼き直して考える。

ここで, Fig. 2 に示す 1D 周期的凹凸曲面構造におけ る自由電子のハミルトン演算子をユークリッド空間 $\left(\mathrm{H}_{\mathrm{E}}\right)$ からリーマン空間 $\left(\mathrm{H}_{\mathrm{R}}\right)$ に焼き直すと,

$$
\mathrm{H}_{\mathrm{E}}=\mathrm{H}_{\mathrm{R}}=\mathrm{H}_{\text {normal }}+\mathrm{H}_{\text {lateral }}
$$

と変換でき, 曲面に対して垂直方向 $\left(\mathrm{H}_{\text {normal }}\right)$ と横方向 $\left(\mathrm{H}_{\text {lateral }}\right)$ のハミルトン演算子に分けることができる。い ま曲面上を動く電子の運動に注目しているので，横方向 のみのハミルトン演算子だけ考えれば良い。ハミルトン 演算子 $\mathrm{H}_{\text {lateral }}$ は，ある曲線座標系 $\left(q^{1}, q^{2}\right)$ を用いて,

$$
\mathrm{H}=-\frac{\hbar^{2}}{2 m^{*}}\left[\frac{1}{\sqrt{g}} \sum_{i, j=1}^{2} \frac{\partial}{\partial q^{i}}\left(\sqrt{g} g^{i j} \frac{\partial}{\partial q^{j}}\right)+\left(h^{2}-k\right)\right]
$$

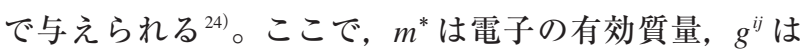
行列 $\left[g_{i j}\right]$ の逆行列成分, $g$ は行列 $\left[g_{i j}\right]$ の行列式を表 
す。 $h$ と $k$ はそれぞれ曲面の平均曲率とガウス曲率を表 し, 計量テンソル $g_{i j}$ の関数でもある。したがって, 曲 面の形状が決まれば，その形状を記述する計量テンソル $g_{i j}$ が決まり, (4) 式のハミルトン演算子が一意に決ま ることになる。上記ハミルトン演算子の［］内の第 1 項は，通常のシュレディンガー方程式でお目にかかるラ プラス演算子 $\triangle$ 極座標表示と同じで，曲線座標系を平 面系に逆変換しても現れるもので, 系の曲面とは直接関 係しない。これに対して, 第 2 項は $\left(h^{2}-k\right)$ で表され る新しいスカラーポテンシャル項で, 曲面の幾何曲率が 誘起するポテンシャルである。このポテンシャルが物性 に影響を与えるかどうか理論的研究が数多く報告されて いるが25 34), 実験的検証は調べる限りにおいて報告さ れていない。

\section{1 次元エキゾチックナノカーボン}

\section{1 理論予想}

ピーナッツ型フラーレンポリマーが $1 \mathrm{D}$ 金属である場 合, Fig. 3 に示すように, 電子はフェルミ液体挙動（フ エルミ分布関数に従う）を示さず，代わりに朝永・ラッ ティンジャー液体（Tomonaga-Luttinger Liquid : TLL）と して振る舞うことが理論的に予想されている ${ }^{35)}$ 。この場 合, 光電子スペクトル形状はエネルギーや温度に対して ベキ乗 (power-law) 則を示し, その TLL 指数 $\alpha$ は 1 末 満になる。

たとえば，金属的性質を示す単層ナノチューブ (SWCNTs) の場合, 光電子スペクトル形状はエネルギ 一および温度に対してべキ乗則を示し，その TLL 指数 $\alpha$ の值は理論予想值 $(0.5)^{36)}$ とほぼ同じ值であることが 報告されている ${ }^{37)}$ 。

さて, (4) 式のハミルトン演算子を使って, Fig. 2 の 自由電子系の電子状態密度 $n(\omega)$ を求めると次式が得ら れる ${ }^{13)}$ 。

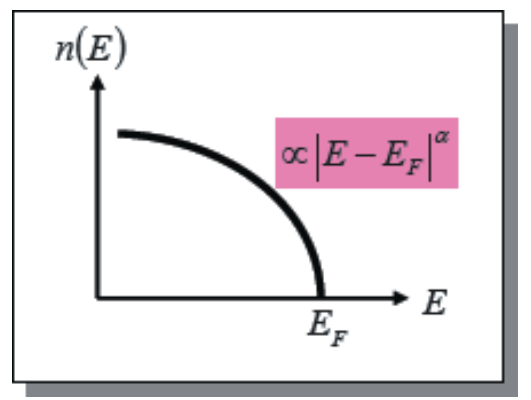

Fig. 3. (color online). Schematic illustration of a power-law dependence of electron density-of-states on binding energy for 1D metal.

$$
\begin{aligned}
& n(\omega) \propto\left|\hbar \omega-E_{\mathrm{F}}\right|^{\alpha} \\
& \alpha=\frac{K+K^{-1}}{2}-1
\end{aligned}
$$

ここで, TLL 指数 $\alpha$ は電子間相互作用の強さを表す TLL パラメーター $K(>0)$ により決まる。詳細は文献 13）を参照されたい。

Fig. 4 に結果を示す。 $\delta r=0$ (凹凸が無いストレート チューブ）のとき，TLL 指数 $\alpha$ の值が 0.5 になるように 種々のパラメーターを調製してある。 $\delta r$ の值を大きく していくと，すなわち，凹凸の度合い（曲率）を大きく していくと, TLL 指数 $\alpha$ の值が単調に増加することが わかる。この増加の原因は, (4)式の右辺第 2 項の曲率 ポテンシャル項によるものである。

\section{2 光電子スペクトル}

銅基板上に作製したピーナッツ型フラーレンポリマー 膜（膜厚 $20 \mathrm{~nm}$ 程度）の $E_{\mathrm{F}}$ 近傍における in situ 高分解 能 (エネルギー分解能 : $12 \mathrm{meV}$ ) 光電子スペクトルの

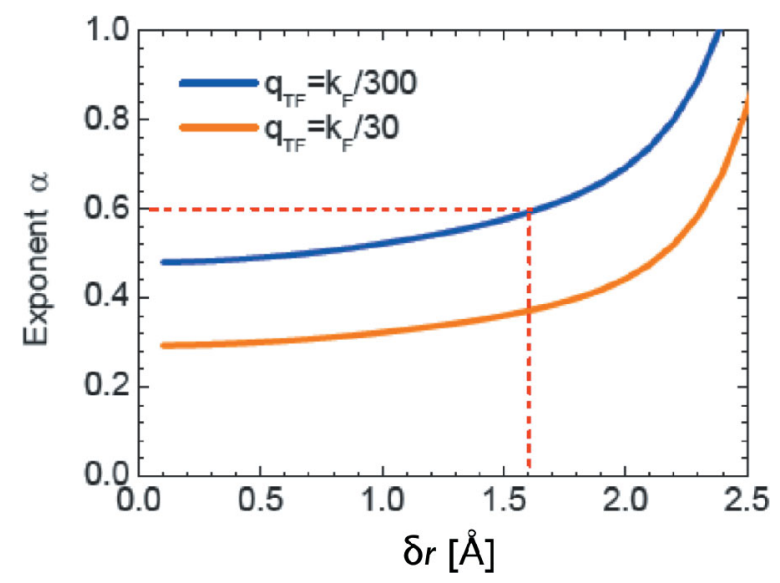

Fig. 4. (color online). Plot of TLL exponent $\alpha$ as a function of the radial modulation degree $\delta r$.

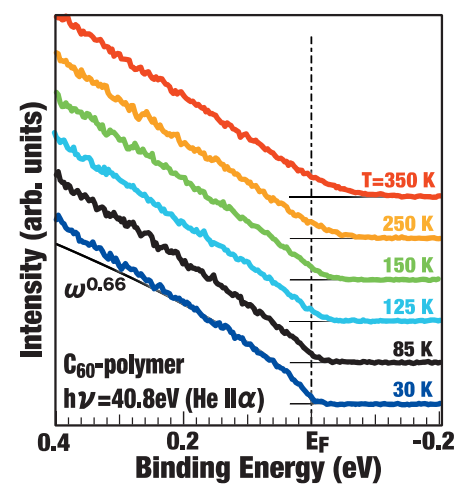

Fig. 5. (color online). Temperature dependence of the photoemission spectra of a $1 \mathrm{D}$ uneven peanut-shaped $\mathrm{C}_{60}$ polymer in the vicinity of the Fermi level $\left(E_{\mathrm{F}}\right)$ [Ref. 18)]. 
温度依存性（30３50 K）を Fig. 5 に示す。実験条件の 詳細については, 紙面の関係で割愛したので, 詳細は文 献 18）を参照されたい。

$350 \mathrm{~K}$ では, 熱的分布による影響のため, スペクトル がフェルミ端（ $E_{\mathrm{F}}$ )を横切っているのに対して, $30 \mathrm{~K}$ では，熱的分布の影響がほとんどなくなり，スペクトル が束縛エネルギーに対してフェルミ端からべキ乗則に従 った依存性を示すことがわかる。TLL 指数 $\alpha$ を求める ために, エネルギーおよび温度と状態密度に関して, $\log \log$ プロットした結果を Fig. 6 に示す。

SWCNTs 同様に, エネルギーと温度に対してべキ乗 則を示したことから，ピーナッツ型フラーレンポリマー は $1 \mathrm{D}$ 金属であり，その TLL 指数 $\alpha$ の值は約 0.6 である ことが得られた ${ }^{18)}$ 。1D 周期的凹凸ピーナッッ型構造 （Fig. 1）の凹凸度 $\delta r$ は in situ 赤外分光スペクトルと第 一原理計算から $0.14 \mathrm{~nm}$ である。Fig. 4 に示すように, $\alpha=0.6$ を与える凹凸度は $\delta r=0.16 \mathrm{~nm}$ であることから， 光電子分光の結果と理論予測結果とは大変良い一致を示 すことがわかる。 (a)

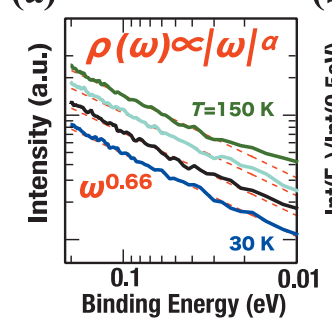

(b)

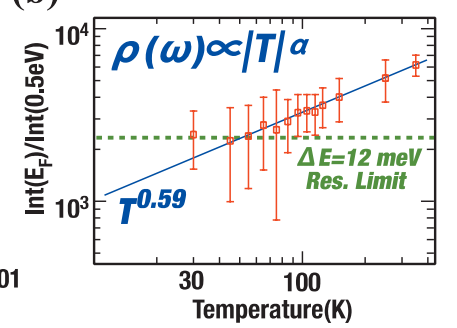

Fig. 6. (color online). The power law dependence of the PES spectral function shown in Fig. 2 on the binding energy (a) and temperature (b) [Ref. 18)].
TLL 指数 $\alpha$ は周期的に変調された外部電場に対して も変化することが報告されている ${ }^{38)}$ 。この系では外部電 場はもちろん無いが, ポリマー内での分極による内部電 場が指数 $\alpha$ に影響する可能性がある。そこで, ポリマ 一内の内部電場を見積もるために, 実際の炭素原子のネ ットワーク構造の凹凸周期構造の節面に近い $\mathrm{P} 08$ の $\mathrm{C}_{120}$ 構造異性体 (一般化 Stone-Wales 転移により得られる 24 個の $\mathrm{C}_{120}$ 安定構造異性体 ${ }^{39}$ の一つ) の第一原理計算した 結果を Fig. 7 に示す ${ }^{18)}$ 。電荷の偏りは， \pm 0.05 程度とほ とんど分極していないことから，この 1D 周期的凹凸曲 面構造においても同程度の分極しか起こっていないと考 えて差し支えない。この程度の分極による周期的電場は 大変小さく, TLLの $\alpha$ の值を変化させることはできな い(数 $10 \mathrm{eV}$ 必要 $)^{38}$ 。

以上の結果から，1D 周期的凹凸曲面構造を有するピ ーナッツ型フラーレンポリマー（1D エキゾチックナ） カーボン）の光電子分光から, 50 年以上前に理論予測 されてきた電子に対するリーマン幾何学的効果を初めて 実証することに成功したと筆者らは考えている。

\section{4. と め}

本稿では, 幾何学的な観点でこれまでにない新しいナ ノカーボン同素体としての $1 \mathrm{D}$ 金属ピーナッツ型フラー レンポリマーについて筆者らの最近の研究成果を紹介し た。電子物性では, 1 次元金属である TomonagaLuttinger 液体（TLL）挙動を示すとともに, TLL 指数の 值が周期的凹凸曲面構造に起因する曲率が誘起するポテ ンシャルにより増加することが初めて明らかになった。 また, 紙面の関係で割愛したが, 光学物性では $1 \mathrm{D}$ 金属 の特徴であるパイエルス転移と良く似た挙動を示す反 面, 転移温度で緩和時間が発散を示さないなど曲面効果 と関係があるかどうか, さらに, 電子輸送特性では低温 領域における可変領域ホッピング伝導機構の解明など,
Negative Charge $-0.059$

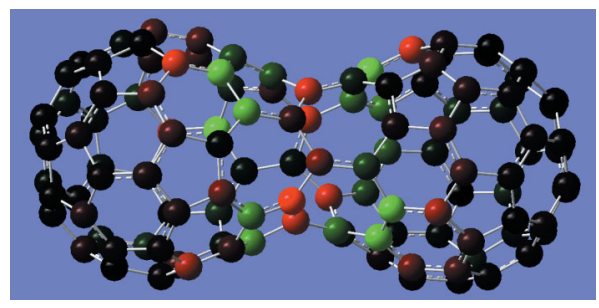

0.074

Positive

Charge
Fig. 7. (color online). The effective charge of P08 $\mathrm{C}_{120}$ isomer obtained using GAUSSIAN03 [Ref. 18)]. 幾何曲率と電子物性との相関関係の解明が多いに期待さ れる(数学的アプローチについては本誌小谷氏の解説を 参照されたい)。

曲面量子物性理論によると, 2 次元凹凸周期構造をも つ半導体では低温領域でウムクラップ過程（この場合, フォノン同士の散乱ではなく電子同士の散乱）による抵 抗増大が予測されている ${ }^{40)}$ 。筆者らがこれまで研究して いる光重合フラーレンポリマーは 2 次元周期的凹凸構造 (Fig. 8 参照) をもつ半導体と見なすことができ ${ }^{41 \sim 46)}$, 曲面量子系として取り扱えることが期待できる。1D 金 属ピーナッツ型フラーレンポリマーとともに, 電子輸送 特性に対する曲率効果の害証が急がれる。

J.W. Milnor（1962 年フィールズ賞受賞）は，1956 年 


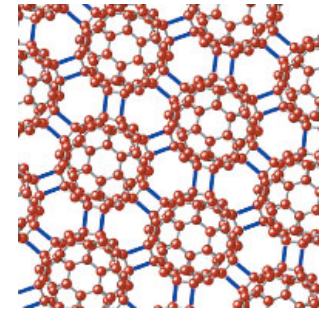

Fig. 8. (color onlone). Schematic illustration of twodimensional semiconducting dumbbell-shaped photopolymerized $\mathrm{C}_{60}$ polymer.

に 7 次元球面（seven-hold spherical surface）には位相同 相であるが微分同相ではない異なる 7 次元球面があるこ とを示し, “エキゾチック球面” (exotic spherical surface) と名付けた ${ }^{47)}$ 。電子の運動エネルギー項は微分演算子で 表され，リーマン空間で取り扱うことにより $1 \mathrm{D}$ 周期的 凹凸構造に沿ったラプラス演算子に現れる曲率項をもつ 1D ピーナッツ型ナノカーボンは, 曲率ポテンシャルを 有しないこれまでのナノカーボンとは異なるという意味 で，筆者らは“エキゾチックナノカーボン” (exoticnanocarbon）と呼んでいる。

1D 周期的凹凸曲面構造だけでなく 2 次元凸凹周期構 造, リング構造, 捻れ構造, Mackay 結晶（Table 1 参 照）など, リーマン空間の量子系として取り扱うことで 初めて理解できる物質群（物性理論の詳細については本 誌島氏の解説を参照されたい）の今後の発見は, 現代幾 何学と物質科学の新しい学術領域を切り開くものであ り，今後の発展に大いに期待したい。

最近, 一見無関係と思われていた現代数学が自然科学 と密接に関係し, 新しい学際分野が期待されている。た とえば, 素数に関するゼー夕関数の非自明なゼロ点の分 布式（リーマン大予想）が原子核のエネルギー間隔を表 す式と一致することが偶然発見され, 素数と核物理現象 との関連性が指摘されている。また, 8 元数（8 種類の 実数単位元で表される数) が超ひも理論を解き明かす最 も有力な手法として期待されている。

このように, 現代数学とサイエンスとの新たな融合領 域はこれからも我々の探究心に刺激を与えてくれるもの と筆者は期待している。

\section{謝辞}

本稿で紹介した研究成果は, 伊藤孝寛博士（名古屋大 学), 島弘幸博士 (山梨大学), 吉岡英生博士 (奈良女子 大学), 木村真一博士 (分子科学研究所) との共同研究 による。また, 文部科学省新学術研究領域 (No. 21200032）の助成により行われた。

\section{文献}

1) A. Einstein : Ann. Phys. 49, 769 (1916).

2) F.W. Dyson, A.S. Eddington and C. Davidson : Philos. Trans. Royal Soc. London 220A, 291 (1920).

3) B.S. DeWitt : Phys. Rev. 85, 653 (1952).

4) Y. Aharonov and D. Bohm : Phys. Rev. 115, 485 (1959).

5) A. Tonomura, N. Osakabe, T. Matsuda, T. Kawasaki, J. Endo, S. Yano and H. Yamada : Phys. Rev. Lett. 56, 792 (1986).

6) J. Onoe, T. Nakayama, M. Aono and T. Hara : Appl. Phys. Lett. 82, 595 (2003).

7) J. Onoe, A. Nakao and A. Hida : Appl. Phys. Lett. 85, 2741 (2004).

8) T.A. Beu, J. Onoe and A. Hida : Phys. Rev. B 72, 155416 (2005).

9) S. Ueda, K. Ohno, Y. Noguchi, S. Ishii and J. Onoe : J. Phys. Chem. B 110, 22374 (2006).

10) T.A. Beu and J. Onoe : Phys. Rev. B 74, 195426 (2006).

11) J. Onoe, T. Itoh, S. Kimura, K. Ohno, Y. Noguchi and S. Ueda : Phys. Rev. B 75, 233410 (2007).

12) Y. Toda, S. Ryuzaki and J. Onoe : Appl. Phys. Lett. 92, 094102 (2008).

13) H. Shima, H. Yoshioka and J. Onoe : Phys. Rev. B 79, 201401 (R) (2009).

14) A. Takashima, J. Onoe and T. Nishii : J. Appl. Phys. 108, 033514 (2010).

15) J. Onoe, A. Takashima and Y. Toda : Appl. Phys. Lett. 97, 241911 (2010).

16) J. Onoe, T. Ito, S. Kimura, H. Shima, Y. Toda and H. Yoshioka : Fullerene, Nanotubes, and Carbon Nanostructures 20, 1 (2012).

17) J. Onoe, A. Takashima, S. Ono, H. Shima and T. Nishii : J. Phys. : Condens. Matter 24, 175405 (2012).

18) J. Onoe, T. Ito, H. Shima, H. Yoshioka and S. Kimura : EPL (Europhys. Lett.) 98, 27001 (2012).

19）曲面上の点 $P$ を通過する様々な曲線でその曲面を切 断した時, 切り口に現れる曲線の曲率の最大值と最 小值の積を「点 $\mathrm{P}$ におけるガウス曲率」と定義す る.

20) A.L. Mackay and H. Terrones : Nature 352, 762 (1991).

21) N. Park, M. Yoon, S. Berber, J. Ihm, E. Osawa and D. Tomanek : Phys. Rev. Lett. 91, 237204 (2003).

22) たとえば, 特集号「曲面量子系のサイエンス」, 表面 科学 30 (12), (2009).

23）たとえば, 尾上 順: “量子論の基礎から学べる量子 化学” (近代科学社, 2012).

24) R.C.T. Da Costa : Phys. Rev. A 23, 1982 (1981).

25) G. Cantele, D. Ninno and G. Iadonisi : Phys. Rev. B 61, 13730 (2000).

26) H. Aoki, M. Koshino, D. Takeda, H. Morise and K. Kuroki : Phys. Rev. B 65, 035102 (2001).

27) M. Encinosa and L. Mott: Phys. Rev. A 68, 014102 (2003).

28) A.V. Chaplik and R.H. Blick : New J. Phys. 6, 33 (2004).

29) N. Fujita and O. Terasaki : Phys. Rev. B 72, 085459 
(2005).

30) M. Koshino and H. Aoki : Phys. Rev. B 71, 073405 (2005).

31) A. Marchi, S. Reggiani, M. Rudan and A. Bertoni : Phys. Rev. B 72, 035403 (2005).

32) J. Gravesen and M. Willatzen : Phys. Rev. A 72, 032108 (2005).

33) B. Jensen : Phys. Rev. A 80, 022101 (2009).

34) G. Cuoghi, G. Ferrari and A. Bertoni : Phys. Rev. B 79, 073410 (2009).

35) J. Voit : Rep. Prog. Phys. 57, 977 (1994).

36) H. Yoshioka : Physica E 18, 212 (2003).

37) H. Ishii, H. Kataura, H. Shiozawa, H. Yoshioka, H. Otsubo, Y. Takayama, T. Miyahara, S. Suzuki, Y. Achiba, M. Nakatake, T. Narimura, M. Higashiguchi, K. Shimada, H. Namatame and M. Taniguchi : Nature 426, 540 (2003).
38) H. Shima, S. Ono and H. Yoshioka : Eur. Phys. J. B 78, 481 (2010).

39) H. Ueno, S. Osawa, E. Osawa and K. Takeuchi : Fullerene Sci. Technol. 6, 319 (1998).

40) S. Ono and H. Shima: Phys. Rev. B 79, 235407 (2009).

41) J. Onoe and K. Takeuchi : Phys. Rev. B 54, 6167 (1996).

42) J. Onoe, A. Nakao and K. Takeuchi : Phys. Rev. B 55, 10051 (1997).

43) J. Onoe and K. Takeuchi : Phys. Rev. Lett. 79, 2987 (1997).

44) K. Esfarjani, Y. Hashi, J. Onoe, K. Takeuchi and Y. Kawazoe : Phys. Rev. B 57, 228 (1998).

45) T. Nakayama, J. Onoe, K. Nakatsuji, J. Nakamura, K. Takeuchi and M. Aono : Surf. Rev. Lett. 6, 1073 (1999).

46) J. Onoe, T. Nakayama, M. Aono and T. Hara : J. Appl. Phys. 96, 443 (2004).

47) J.W. Milnor : Ann. Math. 64, 399 (1956). 